\title{
Coronavirus Disease 2019 (COVID-19): A Haematologist's Perspective
}

\author{
Carmen Ka Man Cheung ${ }^{a}$ Man Fai Law ${ }^{a}$ Grace Chung Yan Lui ${ }^{a}$ b \\ Sunny Hei Wong ${ }^{a, c}$ Raymond Siu Ming Wong ${ }^{a, d}$ \\ aDepartment of Medicine and Therapeutics, Prince of Wales Hospital, The Chinese University of Hong Kong, \\ Hong Kong SAR; ' Stanley Ho Centre for Emerging Infectious Diseases, Faculty of Medicine, The Chinese University \\ of Hong Kong, Hong Kong SAR; ' Institute of Digestive Disease and Department of Medicine and Therapeutics, Li Ka \\ Shing Institute of Health Sciences, The Chinese University of Hong Kong, Hong Kong SAR; ${ }^{\mathrm{d}}$ Sir Y.K. Pao Centre for \\ Cancer, The Chinese University of Hong Kong, Hong Kong SAR
}

\section{Keywords}

COVID-19·SARS-CoV-2 - Lymphopenia · Coagulation · Review

\begin{abstract}
Coronavirus disease 2019 (COVID-19) is affecting millions of patients worldwide. It is caused by the severe acute respiratory syndrome coronavirus 2 (SARS-CoV-2), which belongs to the family Coronaviridae, with $80 \%$ genomic similarities to SARS-CoV. Lymphopenia was commonly seen in infected patients and has a correlation to disease severity. Thrombocytopenia, coagulation abnormalities, and disseminated intravascular coagulation were observed in COVID-19 patients, especially those with critical illness and non-survivors. This pandemic has caused disruption in communities and hospital services, as well as straining blood product supply, affecting chemotherapy treatment and haematopoietic stem cell transplantation schedule. In this article, we review the haematological manifestations of the disease and its implication on the management of patients with haematological disorders.

(c) 2020 S. Karger AG, Basel
\end{abstract}

(C) 2020 S. Karger AG, Basel

www.karger.com/aha

Karger $\stackrel{2}{=}$

\section{Introduction}

Coronavirus disease 2019 (COVID-19) is caused by the severe acute respiratory syndrome coronavirus 2 (SARS-CoV-2), a positive-strand RNA virus belonging to the family Coronaviridae with about $80 \%$ genomic similarities with SARS-CoV [1-3]. The virus is highly contagious, with over 3 million confirmed cases causing more than 190,000 deaths worldwide, reported to the WHO by the end of April 2020 [4-8]. Viral infection is well known to be associated with abnormal haematological parameters. Autopsy of patients who died of COVID-19 showed markedly shrunken spleen with reduced lymphocyte, macrophage proliferation, and phagocytosis [9]. Lymphocytes were also depleted in lymph nodes, and all haematopoietic cell lineages were reduced in the bone marrow. The battle against COVID-19 is likely to be a marathon and the pandemic has a major impact on health care systems in many countries [10]. The virus will continue to pose a risk to people without immunity to it. In this article, we review the haematological manifestations of COVID-19 and its implications on the management of patients with haematological disorders. 


\section{Lymphopenia}

Lymphopenia is a common finding in viral infection. In a multicentre study including 1,099 patients from 552 sites in China, lymphopenia was present in $83.2 \%$ of patients on admission [11]. Many other studies in China reported rates of lymphopenia ranging from $26 \%$ to $80 \%$ (Table 1) [12-30]. In a large US series that included 5,700 patients, lymphopenia was present in around $60 \%(3,387)$ of patients on initial laboratory tests [31]. Lymphopenia was observed on admission in 36.9 and $25 \%$ of COVID-19 patients reported in Singapore and Korea, respectively [32, 33].

Lymphopenia has been consistently found to correlate with the severity of COVID-19 infection and might have a predictive value in the clinical setting. Zhou et al. [34] evaluated risk factors for mortality in a retrospective cohort study involving 191 patients and showed that baseline lymphocyte count was significantly higher in survivors than non-survivors $\left(1.1 \times 10^{9} / \mathrm{L}\right.$ versus $0.6 \times 10^{9} / \mathrm{L}$, $p<0.0001)$. In survivors, lymphocyte count was lowest on day 7 after onset of illness and improved during hospitalization, whereas severe lymphopenia was observed until death in non-survivors. In another retrospective analysis of 95 cases, Zhang et al. [35] demonstrated that the level of lowest lymphocyte count correlated with disease severity and a composite endpoint including intensive care unit (ICU) admission, mechanical ventilation, or death. Among patients with lymphocyte counts $<0.4 \times 10^{9} / \mathrm{L}$, $81.8 \%$ were classified as severe cases and all of them reached the composite endpoint, while in patients with lymphocyte counts $>0.8 \times 10^{9} / \mathrm{L}$, only $11.9 \%$ were severe cases and $9.5 \%$ reached the composite end point. In a retrospective cohort including 201 patients, lymphopenia during the disease course was also reported to be associated with the development of acute respiratory distress syndrome (ARDS) [36]. A significantly higher number of patients requiring treatment in ICU had low lymphocyte counts on presentation [13, 30, 32]. Fan et al. [32] also found that on serial monitoring, the median nadir absolute lymphocyte count in the ICU group was $0.4 \times 10^{9} / \mathrm{L}$ compared to $1.2 \times 10^{9} / \mathrm{L}$ in the non-ICU group. Wang et al. [13] analysed dynamic changes in the haematological parameters of 33 patients from day 1 to day 19 after onset of disease and showed that non-survivors developed more severe lymphopenia over time.

Lymphopenia was frequently encountered in patients requiring ICU care, ranging from $67 \%$ to $85 \%$ in various case series [37-39]. However, there was no significant difference in median lymphocyte counts between survivors and non-survivors in a retrospective observational study involving 52 critically ill patients in Wuhan [39].

Depletion of T cells and NK cells was seen in patients suffering from COVID-19 [32, 40-42]. Lymphopenia on presentation correlated with a high viral load, as reflected by the low cycle threshold value in respiratory samples [43]. Liu et al. [44] analysed the correlation between dynamic changes in the nasopharyngeal viral load and the lymphocyte count. It was found that the higher the RNA load in the nasopharynx, the lower the CD4+ and CD8+ $\mathrm{T}$ lymphocyte count and these changes were closely related to the severity of COVID-19. Jiang et al. [45] evaluated lymphocyte subsets in 103 patients, which revealed that $\mathrm{CD} 3+, \mathrm{CD} 4+$, and CD8+ T cells and NK cells were significantly decreased in COVID-19 patients with a more severe decrease in CD8+ T cells compared with CD4+ T cells. In addition, severe COVID-19 patients showed significant decreases in lymphocyte subset counts compared to mild to moderate patients, especially in $\mathrm{CD} 3+, \mathrm{CD} 4+$, and CD8+ T cells [45]. Another study analysed lymphocyte subsets of 44 patients at presentation and found that both CD4+ and CD8+ T cells were below normal levels in patients with COVID-19 infection, but the decline in CD4+ cells was more pronounced in severe cases [40]. The percentage of naïve helper $\mathrm{T}$ cells $(\mathrm{CD} 3+, \mathrm{CD} 4+$, $\mathrm{CD} 45 \mathrm{RA}+$ ) increased and memory helper $\mathrm{T}$ cells (CD3+, $\mathrm{CD} 4+, \mathrm{CD} 45 \mathrm{RO}+$ ) decreased in severe cases when compared with non-severe cases [40]. Wan et al. [46] analysed lymphocyte subsets in 123 patients on the first day of hospital admission and 1-3 days before discharge. Although there was a greater reduction of $\mathrm{CD} 4+$ and $\mathrm{CD} 8+\mathrm{T}$ cells in the severe group, both CD4+ and CD8+ T cells improved before discharge, suggesting that the cellular immunity had been restored. Liu et al. [47] reported that the decrease of T cells, especially CD8+ T cells, in the severe patient group reached its lowest within the first week during the course of the disease, and then $\mathrm{T}$ cell numbers gradually increased during the second week with recovery to a level comparable to that of the mild patient group in the third week. All the severe patients survived the disease in the study [47]. Another study which compared lymphocyte subsets before and after treatment showed that post-treatment decrease of CD8+ T cells and B cells and increase of $\mathrm{CD} 4+/ \mathrm{CD} 8+$ ratio were independent predictors of poor treatment efficacy [48]. Lower CD4 T lymphocyte counts may predict a longer persistence of SARSCoV-2 RNA in stool, where viral clearance may be further delayed by corticosteroid [49]. Hence, lymphocyte subset may serve as a biomarker for disease evolution, and its monitoring may help to predict disease outcome. 


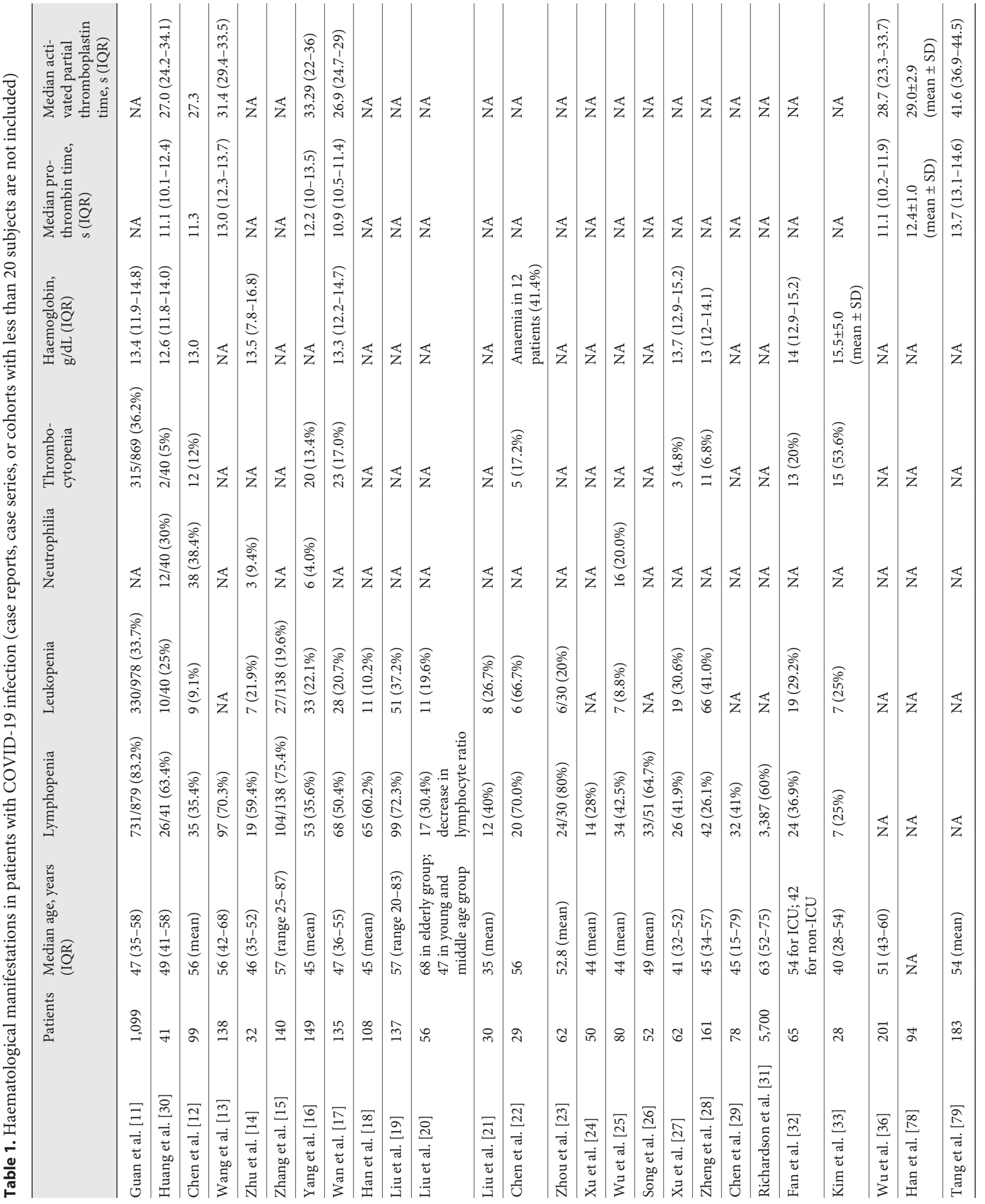


SARS-CoV-2 could trigger necrosis or apoptosis of lymphocytes resulting in lymphopenia. The virus induced NKG2A expression and possibly correlated with functional exhaustion of NK and CD8+ T cells at an early stage, resulting in disease progression [50]. A dysregulated/exuberant innate response also contributed to SARS-CoV-mediated pathology [51]. Cytokine storm with elevation of interleukin (IL)-2R, IL-6, IL-1 $\beta$, IL-8, IL-17, granulocyte colony-stimulating factor (G-CSF), tumour necrosis factor- $\alpha$ (TNF- $\alpha)$, IP10, MCP1, and MIP1 $\alpha$ was seen in COVID-19 patients and may also lead to lymphopenia [52].

\section{Thrombocytopenia}

Compared to lymphopenia, thrombocytopenia is less commonly seen in patients suffering from COVID-19. The reported rates of thrombocytopenia varied from less than $5 \%$ to about $53.6 \%$ (Table 1) $[11,12,16,17,22,27$, $28,30,32,33$ ]. Platelet count has been evaluated as a biomarker to predict the severity of COVID-19 in multiple studies, but the results were confounded by heterogeneity regarding definitions of thrombocytopenia and endpoints used. Two meta-analyses showed that a lower platelet count is associated with an increased risk of severe disease and mortality in patients with COVID-19 and may serve as a marker for progression of illness [53, 54]. In the multicentre study by Guan et al. [11], thrombocytopenia (platelet count $<150 \times 10^{9} / \mathrm{L}$ ) on admission was more commonly seen in severe $(57.7 \%)$ than nonsevere $(31.6 \%)$ patients $[11,55]$. Zhou et al. [34] reported that $20 \%$ of non-survivors had platelet counts less than $100 \times 10^{9} / \mathrm{L}$ on admission compared to only $1 \%$ in survivors $(p<0.0001)$. In contrast, no difference in platelet count on admission was observed between patients requiring ICU care compared with those that did not in other studies $[13,30]$. A study that monitored the sequential changes in platelet count in the first 3 weeks after admission found that there was a gradual drop in platelet counts with a lower nadir among non-survivors compared to survivors (79 [43-129] vs. 203 [155-257], $p<$ 0.001 ) [56]. Dynamic changes of platelets were also reported to be closely related to mortality [57]. An increment in platelets was associated with decrease in mortality, suggesting the role of monitoring platelets in predicting prognosis during hospitalization [58].

A case series including 30 hospitalized COVID-19 patients evaluated the prognostic value of dynamic changes in platelet count and found that a higher platelet-to-lym-

Coronavirus Disease 2019 (COVID-19):

A Haematologist's Perspective phocyte ratio (PLR) at peak platelet count was associated with longer hospital stay and the change in PLR was more prominent in severe patients, which may be caused by cytokine storm provoking inflammation resulting in the stimulation and release of platelet [59]. Yang et al. [60] analysed the predictive role of PLR and showed that a higher PLR was seen in severe patients $(436.5 \pm 329.2)$ compared to non-severe patients $(176.7 \pm 84.2 ; p<0.001)$. Elevated PLR showed a trend of association with disease progression (hazard ratio [HR] 1.023, 95\% CI 0.9211.756 by multivariate Cox regression), but the statistical significance was lost after adjustment of gender and age, limiting its clinical utility [60].

Experience from previous SARS patients, caused by SARS-CoV-1, suggested that coronavirus could cause thrombocytopenia by direct viral infection of bone marrow haematopoietic stem cells via CD13 or CD66a, formation of auto-antibodies and immune complexes, disseminated intravascular coagulopathy (DIC), and consumption of platelet in lung epithelium $[61,62]$. Higher soluble vascular cell adhesion molecule-1 (sVCAM-1) level was found in SARS patients, which enhanced vascular sequestration resulting in thrombocytopenia [63]. Several mechanisms by which COVID-19 causes thrombocytopenia have been proposed, including (a) reduction in platelet production due to direct infection of bone marrow cells by the virus, destruction of bone marrow progenitor cells by cytokine storm, and indirect effect of lung injury; (b) increased platelet destruction by autoantibodies and immune complex; and (c) platelet aggregation in the lungs, resulting in microthrombi and platelet consumption [64]. Cytokine storm of severe disease may lead to secondary haemophagocytic lymphohistiocytosis, which can also result in thrombocytopenia [65].

Thrombocytopenia-associated bleeding is uncommon in COVID-19. Platelet transfusion is recommended in patients with active bleeding and a platelet count less than $50 \times 10^{9} / \mathrm{L}$. For patients at high risk but without active bleeding, platelet transfusion may be considered if the platelet count is less than $20-25 \times 10^{9} / \mathrm{L}$ [66].

\section{Anaemia}

Anaemia is not a major problem in patients suffering from COVID-19 [11, 12, 17, 27, 28, 30, 32, 33]. In a cohort of 572 patients with COVID-19, only $1.6 \%$ of them required blood transfusion, while the transfusion requirement was higher in those admitted to ICU [67]. Various causes of anaemia among patients with COVID-19 have 
been reported, including blood loss during continuous renal replacement therapy and gastrointestinal bleeding with or without anticoagulant use [67]. Autoimmune haemolytic anaemia was also reported in patients with COVID-19 within a timeframe compatible with the development of cytokine storm [68]. SARS-CoV-2 can enter epithelial cells of the gastrointestinal tract via the angiotensin-converting enzyme 2 (ACE2) receptor [69]. Endoscopy revealed oesophageal bleeding caused by erosions and ulcers with detection of SARS-CoV-2 in a patient with severe infection [70]. SARS-CoV-2 was demonstrated in gastric, duodenal, and rectal epithelial cells by RNA detection and intracellular staining of viral nucleocapsid protein [69]. The direct viral invasion into the gastrointestinal tract may result in mucosal damage resulting in bleeding and subsequent need of blood transfusion. Ribavirin has been used as treatment for COVID-19 $[71,72]$. Haemolytic anaemia is one of the major side effects of ribavirin, but most patients did not require transfusion according to previous SARS experience [73]. A randomized controlled trial on the safety and efficacy of its use in COVID-19 patients is ongoing [74].

Adequate haemoglobin level is important to ensure sufficient tissue oxygenation. Phlebotomy by small-volume blood tubes may help to reduce iatrogenic blood loss [75]. Iron replacement should be given to patients with pre-existing iron deficiency anaemia. Use of erythropoiesis-stimulating agents in critically ill patients should be cautious if thromboembolic event is a concern [76]. Decision on allogeneic red cell transfusion should be individualized. A single-unit policy should be followed whenever possible [77].

\section{Coagulation Abnormalities, DIC, and Thromboembolism}

Diverse coagulation abnormalities in COVID-19 infection have been described $[12,13,16,17,30,36,78,79]$. A study in Chongqing showed that the majority of the patients had normal coagulation indexes, probably explained by the fact that $70 \%$ of the included patients had mild disease [17].

DIC is characterized by activation of coagulation and generation and deposition of fibrin, leading to microvascular thrombi deposition in various organs and subsequently multiple organ dysfunction, which predicts mortality in septic patients [80]. Tang et al. [79] studied coagulation parameters in 183 patients suffering from COVID-19 and found that $71.4 \%$ of non-survivors devel- oped overt DIC compared to only $0.6 \%$ among survivors. Patients who died had significantly higher D-dimer, fibrin degradation product levels, and longer PT on admission [79]. The study by Guan et al. [11] showed that $69.4 \%$ patients who reached the primary composite endpoint (ICU admission, mechanical ventilation, or death) had elevated D-dimer level ( $\geq 0.5 \mathrm{mg} / \mathrm{L})$ on admission compared to $44.2 \%$ not reaching the primary endpoint. Wu et al. [36] showed that significant prolongation of PT (median $11.70 \mathrm{~s})$ and higher $\mathrm{D}$-dimer level $(1.16 \mu \mathrm{g} / \mathrm{mL})$ at presentation were observed in patients with ARDS compared to those without (median PT 11.70 vs. $10.60 \mathrm{~s}$, median D-dimer level 1.16 vs. $0.52 \mu \mathrm{g} / \mathrm{mL}, p<0.001$ for both comparisons). Elevated D-dimer level has been shown to be associated with higher mortality rates in various studies $[34,36,57,81]$. In a retrospective study including 343 patients in Wuhan, patients with D-dimer levels $\geq 2 \mu \mathrm{g} /$ $\mathrm{mL}$ on admission had higher mortality compared to those with D-dimer level $<2 \mu \mathrm{g} / \mathrm{mL}$ (HR 51.5, 95\% CI 12.9 206.7) [81]. A D-dimer cut-off value of $\geq 2 \mu \mathrm{g} / \mathrm{mL}$ on admission could predict in-patient mortality with a sensitivity of $92.3 \%$ and a specificity of $83.3 \%$ [81]. Prolongation of PT and markedly elevated D-dimer on admission were associated with poor prognosis and were more commonly seen in patients requiring ICU care $[13,30]$. In addition to coagulation parameters on presentation, dynamic change in coagulation profile could predict disease severity and progression. Tang et al. [79] reported dynamic changes in coagulation parameters from day 1 to day 14 after admission. Non-survivors demonstrated significant increase in $\mathrm{D}$-dimer and fibrin degradation product as well as prolongation of PT by day 10-14, while fibrinogen and antithrombin activity were significantly lower when compared with survivors [79]. Other studies also showed similar findings of a gradual increase in $\mathrm{D}$-dimer levels among non-survivors $[13,34]$. Pooled results in a metaanalysis including 9 studies revealed that $\mathrm{PT}$ and $\mathrm{D}$-dimer levels were significantly higher in patients with severe COVID-19 [82]. Dynamic change in fibrinogen concentration has also been shown to correlate with an increased risk of death [57].

COVID-19 patients with acute respiratory failure presented with severe hypercoagulability due to hyperfibrinogenaemia resulting in increased fibrin formation and polymerization that may predispose to thrombosis [83]. The systemic inflammatory response triggered by viral infection results in an imbalance in homeostatic procoagulant and anticoagulant. Cytokine storm, endothelial dysfunction, von Willebrand factor elevation, Tolllike receptor activation, and tissue-factor pathway activa-
14

Acta Haematol 2021;144:10-23 DOI: $10.1159 / 000510178$
Cheung/Law/Lui/Wong/Wong 
tion may contribute to hypercoagulability [84]. Overactivation of NADPH oxidase-2 (Nox2), resulting in increased reactive oxidant species, is implicated in arterial vasoconstriction, clotting, and platelet activation [85].

Tang et al. [86] provided data in a retrospective study on 449 patients and showed that anticoagulant with unfractionated heparin (10,000-15,000 U/day) or low-molecular-weight heparin (LMWH, enoxaparin 40-60 mg/ day) reduced mortality in patients with sepsis-induced coagulopathy score (a scoring system including platelet count, PT, and major organ failure assessment) of $\geq 4$ (from $64.2 \%$ to $40.0 \%, p=0.029$ ) [86, 87]. A $20 \%$ reduction in mortality was also seen in patients with $\mathrm{D}$-dimer level 6-fold the upper limit of normal who received anticoagulant [87]. Interestingly, no improvement in mortality was seen in anticoagulation therapy for patients with severe pneumonia caused by pathogens other than SARSCoV-2 even with high D-dimer level [88].

A brief report showed that $25 \%$ of 81 patients with severe COVID-19 requiring ICU care developed venous thromboembolism (VTE) [89], which may explain the promising results of anticoagulation. In a cohort of 184 patients admitted to the ICU who received at least standard doses of thromboprophylaxis, the cumulative incidence of VTE and arterial thrombosis was 31\% [90]. Coagulopathy, defined as spontaneous prolongation of PT $>3 \mathrm{~s}$ or APTT $>5 \mathrm{~s}$, was an independent predictor of thrombotic complications (adjusted HR 4.1, 95\% CI 1.99.1). In another multicentre prospective cohort of $150 \mathrm{pa}-$ tients with ARDS admitted to ICU, 25 (16.7\%) of them developed pulmonary embolisms and 3 (2\%) developed deep vein thrombosis despite prophylactic or therapeutic anticoagulation [91]. Since diagnostic tests were only performed based on clinical suspicion, the actual incidence of thrombosis could have been underestimated. Llitjos et al. [92] conducted a retrospective study on 26 patients admitted to ICU with systematic screening of VTE using complete duplex ultrasound performed on days 1-3 of ICU admission, followed by a second scan on day 7 if the first one was negative. The incidence of VTE was $69 \%$ in the group of patients who received anticoagulation [92]. Autopsy of 12 consecutive COVID-19 deaths revealed deep vein thrombosis in 7 patients (58\%) in whom VTE was not suspected before death. Pulmonary embolism was the direct cause of death in 4 patients [93]. Histologic analysis of pulmonary vessels in 7 patients who died from COVID-19 showed widespread thrombosis with microangiopathy and a much higher prevalence of alveolar capillary microthrombi when compared with those who died from influenza-associated respiratory failure [94]. In addition to VTE, arterial thromboses such as acute myocardial infarction have been reported [95]. Large vessel stroke can be a presenting feature in young patients [96]. In a retrospective study of 214 hospitalized patients from Wuhan, $5.7 \%$ of the severe patients suffered from acute cerebrovascular disease [97]. Hypercoagulability was also demonstrated in ICU patients with respiratory failure by thromboelastography [98]. All these findings suggested a pro-coagulant tendency in COVID-19 patients, especially if critically ill.

Middeldorp et al. [99] administered thromboprophylaxis to all patients admitted for COVID-19. Patients admitted to the general ward received nadroparin 2,850 IU once daily or 5,700 IU for patients with a body weight of $\geq 100 \mathrm{~kg}$. From April 3 onwards, the dose of anticoagulation in ICU patients was doubled. Symptomatic VTE was detected in 21 out of $75(28 \%)$ ICU patients and 4 out of $123(3.3 \%)$ ward patients (sub-distribution hazard ratios 3.9; 95\% CI 1.3-12) [99]. Lodigiani et al. [100] studied venous and arterial thromboembolic complications in 388 hospitalized patients. Thromboprophylaxis was used in all ICU patients and 75\% of those on the general ward. Eight events occurred in ICU patients (16.7\%; 95\% CI $8.7-29.6 \%$ ), while 20 events occurred in patients on the general ward (6.4\%; 95\% CI 4.2-9.6\%), corresponding to cumulative rates of 27.6 and $6.6 \%$, respectively. Importantly, 7 events in the general ward occurred in patients with cancer, highlighting that additional risk factors might further increase the risks of VTE [100]. Racial difference on thrombotic risk should also be taken into consideration [101].

The International Society on Thrombosis and Haemostasis (ISTH) suggested all patients (including non-critically ill) who require hospital admission for COVID-19 infection should receive a prophylactic dose of LMWH unless contraindicated (Table 2) [102]. LMWH was the preferred drug of choice due to a high instability of international normalized ratio for vitamin $\mathrm{K}$ antagonists and drug-drug interaction between direct oral anticoagulants and anti-viral agents [103]. The American Society of Hematology (ASH) recommended all hospitalized patients with COVID-19 should receive pharmacological thromboprophylaxis. If it is contraindicated or unavailable, mechanical prophylaxis should be implemented [104]. However, the recommendations of pharmacological thromboprophylaxis on non-critically ill patients are still controversial $[105,106]$. We recommend physicians stay vigilant to thrombotic complication. Decision on thromboprophylaxis should also be based on clinical judgement 
Table 2. Recommendations by International Society of Thrombosis and Haemostasis (ISTH) on management of coagulopathy in COVID-19 patients [101]

\begin{tabular}{ll}
\hline Scenario & Recommendations \\
\hline $\begin{array}{l}\text { Monitoring of } \\
\text { coagulation } \\
\text { markers }\end{array}$ & $\begin{array}{l}\text { Monitor D-dimers, PT, platelet count, and } \\
\text { fibrinogen can help to stratify patients who } \\
\text { may need admission and close monitoring }\end{array}$ \\
\hline $\begin{array}{l}\text { Thrombo- } \\
\text { prophylaxis }\end{array}$ & $\begin{array}{l}\text { Prophylactic dose LMWH should be given to } \\
\text { all patients (including non-critically ill) who } \\
\text { require hospital admission unless contrain- } \\
\text { dicated (active bleeding and platelet count } \\
\left.<25 \times 10^{9} / \mathrm{L}\right)\end{array}$ \\
\hline $\begin{array}{l}\text { Management } \\
\text { of bleeding }\end{array}$ & $\begin{array}{l}\text { Transfuse and aim platelet count above } 50 \\
\times 10^{9} / \mathrm{L} \text {; fibrinogen above } 2.0 \mathrm{~g} / \mathrm{L} ; \mathrm{PT}<1.5\end{array}$ \\
\hline
\end{tabular}
time.

LMWH, low-molecular-weight heparin; PT, prothrombin

and other risk factors, such as prolonged immobilization, active malignancy, obesity, previous history of VTE, and ethnicity. The efficacy, safety, and optimal dosage of anticoagulation in non-critically ill COVID-19 patients need to be confirmed by prospective studies. A more recent consensus statement recommended VTE risk assessment for non-critically ill patients, and only to consider pharmacological thromboprophylaxis in patients with a moderate to high risk of VTE [107].

\section{Impact of COVID-19 on Blood Product Supply}

A significant reduction of blood donations has been reported after the outbreak [108]. Possible reasons include lockdown, stay-at-home order, anxiety for volunteer donors to attend blood donation centres, and additional deferral policy on travel history. The number of eligible donors may further decrease if the outbreak continues to evolve. Establishment of a crisis system to reduce usage (e.g., deferring elective surgery), coordination of blood products delivery to areas with a shortage, use of social media to promote blood donation, etc. might help to overcome the crisis of paucity in blood supply [109]. If the supply of blood product is limited, there may be a need to adopt a more restrictive blood transfusion approach. Transfusion alternatives such as use of iron supplement in iron deficiency anaemia and erythropoiesisstimulating agents should be encouraged. Currently there is no reported case of transmission of the coronavirus from donor to recipient through blood product transfusion or cellular therapies, but given that SARS-CoV-2 RNA was detected in the serum of COVID-19 patients [30], the actual risk of transfusion transmission of SARSCoV-2 remains unknown [110]. There is no additional screening test for blood donors recommended by the American Association of Blood Banks (AABB) at the moment [111]. Use of riboflavin and ultraviolet light-based photochemical treatment to plasma and platelet products may be effective in reducing the theoretical risk of transfusion-transmitted SARS-CoV-2 [112].

\section{How Do We Manage Patients with Haematological Disorder during the Pandemic?}

The COVID-19 pandemic poses a big challenge for the medical community, with a great impact on management of patients with haematological conditions. In a cohort study of 128 hospitalized subjects with haematological cancers at two centres in Wuhan, they have a similar rate of COVID-19 compared with normal health care providers but have more severe disease and a higher case fatality rate $[113,114]$. Non-hospitalized patients with haematological cancers may also have a higher chance of developing symptomatic COVID-19. In a study using a questionnaire to evaluate 530 subjects with chronic myeloid leukaemia in Hubei, prevalence of COVID-19 in chronic myeloid leukaemia patients was 9-fold higher than the $0.1 \%$ reported in normal $[114,115]$. Chemotherapy and transplant schedules have been affected during the outbreak when hospitals are overwhelmed by confirmed COVID-19 cases. The huge demand in isolation facilities compromises the care of patients who have received myelosuppressive therapy complicated with profound neutropenia requiring isolation rooms and prolonged hospitalization. Treatment may also be deferred due to lockdown, quarantine order, disrupted medical health care service, shortage of isolation bed and blood product, and phobia towards attending hospital.

Delay in treatment may have a negative impact on the clinical conditions and outcomes of patients, especially those with more aggressive diseases. Their need for timely treatment should not be neglected. In general, less essential service should be postponed [116] in order to reduce the number of patients requiring hospital care so as to minimise risk of nosocomial COVID-19 infection, to conserve personal protective equipment for high-risk clinical activities, and to maintain the capacity of the health care system.
Cheung/Law/Lui/Wong/Wong 
Table 3. Suggested strategies in the management of haematological malignancies under COVID-19 pandemic [103, 114-116]

\section{Disease Management recommendation}

AML Induction and consolidation

- All patients should be tested for COVID-19 prior to initiation of intensive chemotherapy

- Delay treatment if possible for patients positive for COVID-19

- Standard induction therapy should be offered to eligible patients

- Intermediate-dose cytarabine $\left(1.5 \mathrm{~g} / \mathrm{m}^{2}\right)$ or decreasing the number of consolidation cycles can be considered in patients who achieve complete remission

Salvage therapy

- Intensive re-inductions should be performed according to the algorithms of the individual centre

- For patients without proliferative disease or significant transfusion dependence, therapy may be temporarily postponed

HSCT

- Consider cryopreservation of donor cells prior to the start of conditioning

APL - Standard regime including ATRA and ATO should be given

- Prophylactic dexamethasone should be considered for patients at high risk of differentiation syndrome

ALL Induction and consolidation

- All patients should be tested for COVID-19 prior to initiation of intensive chemotherapy

- Delay treatment if possible for patients positive for COVID-19; intrathecal chemotherapy may be given if CNS symptoms are present

- Philadelphia chromosome negative

- Proceed with standard curative induction therapy

- Dose reduction may be considered for patients at high risk for complications

- Philadelphia chromosome positive

- Consider TKI with minimal steroid exposure as initial treatment

Salvage therapy

- Treatment that can be administered at outpatient setting such as inotuzumab or blinatumomab should be considered for B-ALL

HSCT

- Allogeneic HSCT should be considered for patient who achieved CR2 despite the pandemic

NHL Aggressive lymphoma

- Standard regime such as R-CHOP for diffuse large B-cell lymphoma and DA-EPOCH-R for double-hit and primary mediastinal B-cell lymphomas should be offered

- Dose reduction or limiting treatment cycle can be considered for elderly or early stage disease

- Consider subcutaneous rituximab to reduce patient's time spent in clinical area

- For relapse/refractory disease, admission for ASCT may be delayed if another cycle of outpatient chemotherapy can be administered

Indolent lymphoma

- Treatment deferral with close monitoring is recommended for asymptomatic patients

- When treatment is indicated, consider rituximab monotherapy rather than chemoimmunotherapy

- Treatment options that minimize clinic or chemotherapy unit visits are preferred

HL Initial therapy

- Strategies to reduce the risk of bleomycin pneumonitis should be prioritized especially during the pandemic

- Standard treatment such as ABVD, AAVD, and radiotherapy should be given

Salvage therapy

- Consider outpatient second-line gemcitabine-based treatment, brentuximab vedotin or PD1 antibodies 
Table 3 (continued)

Disease Management recommendation

CML Initial therapy

- TKI should be initiated in newly diagnosed patients without delay

Chronic phase

- Prophylactic interruption of TKI is not recommended

- Initiation TFR attempts during the epidemic phase should be postponed

Accelerated phase and blast crisis

- Transformation to accelerated phase while on therapy can be managed with an appropriate TKI and proper monitoring

- For blast phase CML, intensive TKI-based combination therapy should be considered for younger patients; single agent

with TKI may be advisable for those with higher risk of SARS-CoV-2 infection and complications

Confirmed COVID-19

- For patients suffering from non-severe COVID-19, interruption of TKI treatment is not recommended

- For severe disease, TKI interruption should be discussed on a case-to-case basis

- Caution should be taken with the drug-drug interactions between treatment of SARS-CoV-2 infection and TKI

CLL Initial therapy

- Postpone treatment initiation if possible

- Treatments that can be provided in the outpatient setting are preferred

- Try to limit use of monoclonal antibodies or initiation of venetoclax if possible

Confirmed COVID-19

- For patients with mild COVID-19 disease, modification of therapy is not necessary

- Treatment modification in patients with severe symptoms should depend on weighing the aggressiveness of CLL and risk of COVID-19 complication

- Discontinuation of BCR signalling inhibitor may result in CLL flare and cytokine release

MM General recommendation

- Patients should be tested for COVID-19 before hospital admission, starting a new treatment, cell apheresis, or ASCT in countries with high spread of SARS-CoV-2

- Treatment re-schedule and de-intensification can be considered for responding patients

- Patients receiving bisphosphonates should reduce frequency of drug infusion to every 3 months or temporarily withheld

Transplant eligible

- Bortezomib, lenalidomide, or daratumumab-based triplet therapy for 6-12 cycles should be offered

- For patients with standard risk disease, delay ASCT by additional induction cycles and/or lenalidomide maintenance

- Patients with high-risk disease may proceed with ASCT after exclusion of COVID-19 infection

Transplant ineligible

- Dexamethasone should be reduced to $20 \mathrm{mg}$ weekly

- All-oral drug combinations, e.g., lenalidomide with dexamethasone, are preferred

- Addition of bortezomib or daratumumab can be considered for patients with high-risk disease

Relapsed/refractory

- Watchful waiting may be considered for biochemical relapses

- Orally administered agents (such as ixazomib, lenalidomide, pomalidomide, and panobinostat) should be considered

- Modify treatment regime to minimize clinic/hospital visit, such as once weekly instead of twice weekly bortezomib/

carfilzomib and monthly daratumumab infusions are recommended

Confirmed COVID-19

- If anti-myeloma treatment has been started, therapy might be continued for asymptomatic COVID-19 infection, although pausing of treatment is also an option; steroids and drugs inducing lymphopenia should be de-intensified

- For symptomatic infection, treatment should be interrupted and steroids should be tapered to zero until full recovery from COVID-19

AAVD, brentuximab vedotin, adriamycin, vinblastine, dacarbazine; ABVD, adriamycin, bleomycin, vinblastine, dacarbazine; ALL, acute lymphoblastic leukaemia; AML, acute myeloid leukaemia; APL, acute promyelocytic leukaemia; ASCT, autologous stem cell transplantation; ATRA, all-trans-retinoic acid; ATO, arsenic trioxide; BCR, B-cell receptor; CLL, chronic lymphocytic leukaemia; CML, chronic myeloid leukaemia; CNS, central nervous system; CR, complete remission; DA-EPOCH-R, dose-adjusted etoposide, prednisolone, vincristine, cyclophosphamide, doxorubicin-rituximab; HL, Hodgkin lymphoma; HSCT, haematopoietic stem cell transplantation; MM, multiple myeloma; NHL, non-Hodgkin lymphoma; $\mathrm{PD}-1$, programmed cell death protein 1; R-CHOP, rituximabcyclophosphamide, doxorubicin, vincristine, prednisolone; TFR, treatment-free remission; TKI, tyrosine kinase inhibitor. 
Table 4. Recommendations for haematopoietic stem cell transplantation during COVID-19 pandemic [123]

For transplant candidate

- For confirmed COVID-19 patients with high-risk malignancy, HSCT should be deferred for a minimum of 14 days until the patient is asymptomatic and has two negative virus PCR swabs taken at least $24 \mathrm{~h}$ apart

- In patients infected with COVID-19 with low-risk malignancy, a 3-month HSCT deferral is recommended

- For patients who had close contact with a person diagnosed with COVID-19, any transplant procedures (PBSC mobilization, BM harvest, conditioning) shall not be performed within at least 14 days from the last contact

\section{For donor}

- Donors should have been asymptomatic for at least 14 days before donation and a negative test for COVID-19 is recommended

- In case of diagnosis of COVID-19, donor should be excluded from donation. Stem cell collection should be deferred for at least 28 days after recovery. If the recipient's need for transplant is urgent and the donor is completely well and there are no suitable alternative donors, an earlier collection may be considered if local public health requirements permit, subject to careful risk assessment

- In case of close contact with a person diagnosed with SARS-CoV-2, the donor shall be excluded from donation for at least 28 days; if the patient's need for transplant is urgent, the donor is completely well, a test is negative for SARS-CoV-2, and there are no suitable alternative donors, earlier collection may be considered subject to careful risk assessment

BM, bone marrow; HSCT, haematopoietic stem cell transplantation; PBSC, peripheral blood stem cell; PCR, polymerase chain reaction.

Life-saving chemotherapy for conditions such as acute leukaemia or aggressive lymphoma should not be delayed. Watchful waiting approach may be considered for patients with indolent diseases if the risk of severe COVID-19 infection outweighs treatment benefit, while single-agent monoclonal antibody instead of combination chemoimmunotherapy can be considered in patients who require treatment. Oral formulation is preferred to intravenous injection to minimize hospital visit. Prioritization and triage of anti-cancer therapy should be based on disease- and patient-specific considerations through communication with specialists and patients [117].

Recommendations on induction, consolidation, and salvage therapies on haematological malignancy during the pandemic by the ASH, European Hematology Association (EHA), and International Myeloma Society are summarized in Table 3 [104, 118-120].

Coronavirus Disease 2019 (COVID-19):

A Haematologist's Perspective
Primary prophylaxis using G-CSF in patients receiving intensive chemotherapy reduces the risk of febrile neutropenia and the risk of hospitalization and thus should be considered [121, 122]. Effective non-immunosuppressive treatments, such as intravenous immunoglobulin and thrombopoietin receptor agonists, may be considered in lieu of high-dose steroid for patients with immune thrombocytopenia purpura and severe thrombocytopenia. If patients are stable on low doses of immunosuppressive drugs, no modification of drug regimen is needed.

Infection prevention measures such as hand hygiene in ambulatory chemotherapy centres or clinics should be implemented. Screening procedures, including questionnaire on respiratory symptoms, travel and contact history, and measuring of body temperature, should be performed for patients and hospital visitors [123]. Patients may benefit from increased surveillance of SARS-CoV-2 infection and protective isolation [113-115]. Psychosocial support should be provided where possible, when measures of social distancing might have affected the well-being of patients with haematological malignancies.

Great obstacles on allogeneic haematopoietic stem cell transplantation have been encountered during the COVID-19 outbreak. Closure of international borders, travel restriction, and shutdown of air travel has affected international donor travel and the shipping of cellular products. Cryopreserved stem cell transplantation during the pandemic can be considered if alternative cellular products or donors are not available and does not appear to have a negative impact on the long-term outcome [124, 125]. Appropriate measures such as home quarantine and screening of donors for COVID-19 prior to donation should be implemented in areas with a high frequency of SARS-CoV-2 infection [126]. All transplant recipients should also be tested negative for SARS-CoV-2 irrespective of respiratory symptoms before initiating conditioning chemotherapy [127]. Treatment cycles may be increased to achieve a deeper remission before proceeding to allogeneic haematopoietic stem cell transplantation. The European Society for Blood and Marrow Transplantation (EBMT) proposed suggestions on haematopoietic stem cell transplantation during the COVID-19 pandemic, which is shown in Table 4 [127].

In summary, the COVID-19 disease has had notable haematological manifestations. Lymphopenia, thrombocytopenia, and coagulation abnormalities on presentation and during the disease courses have been associated with poor outcomes, and serial monitoring is recommended. Physicians should stay vigilant against VTE and 
consider pharmacological thromboprophylaxis in highrisk patients. Changes in clinical practice are unavoidable in the current pandemic. Treatment decision should be tailored on an individual basis to minimize risk of infection without jeopardizing the disease outcome.

\section{Conflict of Interest Statement}

The authors have no relevant conflict of interest to disclose.

\section{Author Contributions}

Carmen K.M. Cheung: acquisition, analysis, and interpretation of data/references; drafting and approving the manuscript. Man Fai Law: acquisition, analysis, and interpretation of data/references; drafting and approving the manuscript. Grace C.Y. Lui: analysis, interpretation of data/references; revising critically and approving the manuscript. Sunny Hei Wong: analysis, interpretation of data/references; revising critically and approving the manuscript. Raymond S.M. Wong: analysis, interpretation of data/references; drafting, revising critically, and approving the manuscript.

\section{References}

1 Li G, Fan Y, Lai Y, Han T, Li Z, Zhou P, et al. Coronavirus infections and immune responses. J Med Virol. 2020 Apr;92(4):424-32.

2 Wu F, Zhao S, Yu B, Chen YM, Wang W, Song ZG, et al. A new coronavirus associated with human respiratory disease in China. Nature. 2020 Mar;579(7798):265-9.

3 Zhou P, Yang XL, Wang XG, Hu B, Zhang L, Zhang W, et al. A pneumonia outbreak associated with a new coronavirus of probable bat origin. Nature. 2020 Mar;579(7798):270-3.

4 WHO Health Emergency Dashboard Coronavirus (COVID-19): World Health Organization (WHO). Available from: https://covid19.who.int. Accessed on 30 April 2020.

5 Li Q, Guan X, Wu P, Wang X, Zhou L, Tong $\mathrm{Y}$, et al. Early Transmission Dynamics in Wuhan, China, of Novel Coronavirus-Infected Pneumonia. N Engl J Med. 2020 Mar;382(13): 1199-207.

$6 \mathrm{Wu}$ JT, Leung K, Leung GM. Nowcasting and forecasting the potential domestic and international spread of the 2019-nCoV outbreak originating in Wuhan, China: a modelling study. Lancet. 2020 Feb;395(10225):689-97.

7 Zhang S, Diao M, Yu W, Pei L, Lin Z, Chen D. Estimation of the reproductive number of novel coronavirus (COVID-19) and the probable outbreak size on the Diamond Princess cruise ship: A data-driven analysis. Int J Infect Dis. 2020 Apr;93:201-4.

8 Zhao S, Lin Q, Ran J, Musa SS, Yang G, Wang $\mathrm{W}$, et al. Preliminary estimation of the basic reproduction number of novel coronavirus (2019-nCoV) in China, from 2019 to 2020: A data-driven analysis in the early phase of the outbreak. Int J Infect Dis. 2020 Mar;92:214-7.

9 Chinese Clinical Guidance for COVID-19 Pneumonia Diagnosis and Treatment. In: Commission $\mathrm{CNH}$, editor. 7th edition ed2020.

10 Rosenbaum L. The Untold Toll - The Pandemic's Effects on Patients without Covid-19. N Engl J Med. 2020 Jun;382(24):2368-71.

11 Guan WJ, Ni ZY, Hu Y, Liang WH, Ou CQ, He JX, et al.; China Medical Treatment Expert Group for Covid-19. Clinical Characteristics of Coronavirus Disease 2019 in China. N Engl J Med. 2020 Apr;382(18):1708-20.
12 Chen N, Zhou M, Dong X, Qu J, Gong F, Han $\mathrm{Y}$, et al. Epidemiological and clinical characteristics of 99 cases of 2019 novel coronavirus pneumonia in Wuhan, China: a descriptive study. Lancet. 2020 Feb;395(10223):507-13.

13 Wang D, Hu B, Hu C, Zhu F, Liu X, Zhang J, et al. Clinical Characteristics of 138 Hospitalized Patients with 2019 Novel CoronavirusInfected Pneumonia in Wuhan. China: JAMA; 2020. https://doi.org/10.1001/jama. 2020.1585.

14 Zhu W, Xie K, Lu H, Xu L, Zhou S, Fang S. Initial clinical features of suspected coronavirus disease 2019 in two emergency departments outside of Hubei, China. J Med Virol. 2020 Mar;jmv.25763.

15 Zhang JJ, Dong X, Cao YY, Yuan YD, Yang YB, Yan YQ, et al. Clinical characteristics of $140 \mathrm{pa}-$ tients infected with SARS-CoV-2 in Wuhan, China. Allergy. 2020 Jul;75(7):1730-41.

16 Yang W, Cao Q, Qin L, Wang X, Cheng Z, Pan A, et al. Clinical characteristics and imaging manifestations of the 2019 novel coronavirus disease (COVID-19): a multi-center study in Wenzhou city, Zhejiang, China. J Infect. 2020 Apr;80(4):388-93.

17 Wan S, Xiang Y, Fang W, Zheng Y, Li B, Hu $\mathrm{Y}$, et al. Clinical features and treatment of COVID-19 patients in northeast Chongqing. J Med Virol. 2020 Jul;92(7):797-806.

18 Han R, Huang L, Jiang H, Dong J, Peng H, Zhang D. Early Clinical and CT Manifestations of Coronavirus Disease 2019 (COVID-19) Pneumonia. AJR Am J Roentgenol. 2020 Mar;215(2):1-6.

19 Liu K, Fang YY, Deng Y, Liu W, Wang MF, Ma JP, et al. Clinical characteristics of novel coronavirus cases in tertiary hospitals in $\mathrm{Hu}$ bei Province. Chin Med J (Engl). 2020 May; 133(9):1025-31.

20 Liu K, Chen Y, Lin R, Han K. Clinical features of COVID-19 in elderly patients: a comparison with young and middle-aged patients. J Infect. 2020 Jun;80(6):e14-8.

21 Liu M, He P, Liu HG, Wang XJ, Li FJ, Chen S, et al. [Clinical characteristics of 30 medical workers infected with new coronavirus pneumonia]. Zhonghua Jie He He Hu Xi Za Zhi. 2020 Feb;43(0):E016.
22 Chen L, Liu HG, Liu W, Liu J, Liu K, Shang J, et al. [Analysis of clinical features of $29 \mathrm{pa}$ tients with 2019 novel coronavirus pneumonia]. Zhonghua Jie He He Hu Xi Za Zhi. 2020 Feb;43(0):E005.

23 Zhou S, Wang Y, Zhu T, Xia L. CT Features of Coronavirus Disease 2019 (COVID-19) Pneumonia in 62 Patients in Wuhan, China. AJR Am J Roentgenol. 2020 Jun;214(6):128794.

$24 \mathrm{Xu}$ YH, Dong JH, An WM, Lv XY, Yin XP, Zhang JZ, et al. Clinical and computed tomographic imaging features of novel coronavirus pneumonia caused by SARS-CoV-2. J Infect. 2020 Apr;80(4):394-400

$25 \mathrm{Wu}$ J, Wu X, Zeng W, Guo D, Fang Z, Chen $\mathrm{L}$, et al. Chest CT Findings in Patients With Coronavirus Disease 2019 and Its Relationship With Clinical Features. Invest Radiol. 2020 May;55(5):257-61.

26 Song F, Shi N, Shan F, Zhang Z, Shen J, Lu H, et al. Emerging 2019 Novel Coronavirus (2019-nCoV) Pneumonia. Radiology. 2020 Apr;295(1):210-7.

27 Xu XW, Wu XX, Jiang XG, Xu KJ, Ying LJ, Ma $\mathrm{CL}$, et al. Clinical findings in a group of patients infected with the 2019 novel coronavirus (SARS-Cov-2) outside of Wuhan, China: retrospective case series. BMJ. 2020 Feb; 368:m606.

28 Zheng F, Tang W, Li H, Huang YX, Xie YL, Zhou ZG. Clinical characteristics of 161 cases of corona virus disease 2019 (COVID-19) in Changsha. Eur Rev Med Pharmacol Sci. 2020 Mar;24(6):3404-10.

29 Chen X, Yang Y, Huang M, Liu L, Zhang X, $\mathrm{Xu}$ J, et al. Differences between COVID-19 and suspected then confirmed SARS-CoV2-negative pneumonia: A retrospective study from a single center. J Med Virol. 2020 Apr. https://doi.org/10.1002/jmv.25810.

30 Huang C, Wang Y, Li X, Ren L, Zhao J, Hu Y, et al. Clinical features of patients infected with 2019 novel coronavirus in Wuhan, China. Lancet. 2020 Feb;395(10223):497-506. 
31 Richardson S, Hirsch JS, Narasimhan M, Crawford JM, McGinn T, Davidson KW, et al.; and the Northwell COVID-19 Research Consortium. Presenting Characteristics, Comorbidities, and Outcomes Among $5700 \mathrm{~Pa}$ tients Hospitalized With COVID-19 in the New York City Area. JAMA. 2020 Apr; 323(20):2052.

32 Fan BE, Chong VC, Chan SS, Lim GH, Lim KG, Tan GB, et al. Hematologic parameters in patients with COVID-19 infection. Am J Hematol. 2020 Jun;95(6):E131-4.

33 Kim ES, Chin BS, Kang CK, Kim NJ, Kang YM, Choi JP, et al.; Korea National Committee for Clinical Management of COVID-19. Clinical Course and Outcomes of Patients with Severe Acute Respiratory Syndrome Coronavirus 2 Infection: A Preliminary Report of the First 28 Patients from the Korean Cohort Study on COVID-19. J Korean Med Sci. 2020 Apr;35(13):e142.

34 Zhou F, Yu T, Du R, Fan G, Liu Y, Liu Z, et al. Clinical course and risk factors for mortality of adult inpatients with COVID-19 in Wuhan, China: a retrospective cohort study. Lancet. 2020 Mar;395(10229):1054-62.

35 Zhang G, Zhang J, Wang B, Zhu X, Wang Q, Qiu S. Analysis of clinical characteristics and laboratory findings of 95 cases of 2019 novel coronavirus pneumonia in Wuhan, China: a retrospective analysis. Respir Res. 2020 Mar; 21(1):74.

36 Wu C, Chen X, Cai Y, Xia J, Zhou X, Xu S, et al. Risk Factors Associated with Acute Respiratory Distress Syndrome and Death in $\mathrm{Pa}$ tients With Coronavirus Disease 2019 Pneumonia in Wuhan, China. JAMA Intern Med. 2020 Mar 13;180(7):1-11.

37 Arentz M, Yim E, Klaff L, Lokhandwala S, Riedo FX, Chong M, et al. Characteristics and Outcomes of 21 Critically Ill Patients With COVID-19 in Washington State. JAMA. 2020 Mar;323(16):1612.

38 Bhatraju PK, Ghassemieh BJ, Nichols M, Kim $\mathrm{R}$, Jerome KR, Nalla AK, et al. Covid-19 in Critically Ill Patients in the Seattle Region Case Series. N Engl J Med. 2020 May;382(21): 2012-22.

39 Yang X, Yu Y, Xu J, Shu H, Xia J, Liu H, et al. Clinical course and outcomes of critically ill patients with SARS-CoV-2 pneumonia in Wuhan, China: a single-centered, retrospective, observational study. Lancet Respir Med. 2020 May;8(5):475-81.

40 Qin C, Zhou L, Hu Z, Zhang S, Yang S, Tao Y, et al. Dysregulation of immune response in patients with COVID-19 in Wuhan, China. Clin Infect Dis. 2020 Mar 12;ciaa248.

41 Chen G, Wu D, Guo W, Cao Y, Huang D, Wang $\mathrm{H}$, et al. Clinical and immunological features of severe and moderate coronavirus disease 2019. J Clin Invest. 2020 May; 130(5): $2620-9$.
42 Liu Z, Long W, Tu M, Chen S, Huang Y, Wang S, et al. Lymphocyte subset (CD4+, $\mathrm{CD} 8+)$ counts reflect the severity of infection and predict the clinical outcomes in patients with COVID-19. J Infect. 2020 Apr; S0163-4453(20)30182-1.

43 Liu Y, Yang Y, Zhang C, Huang F, Wang F, Yuan J, et al. Clinical and biochemical indexes from 2019-nCoV infected patients linked to viral loads and lung injury. Sci China Life Sci. 2020 Mar;63(3):364-74.

44 Liu Y, Liao W, Wan L, Xiang T, Zhang W. Correlation between Relative Nasopharyngeal Virus RNA Load and Lymphocyte Count Disease Severity in Patients with COVID-19. Viral Immunol. 2020 Apr;vim.2020.0062.

45 Jiang M, Guo Y, Luo Q, Huang Z, Zhao R, Liu $S$, et al. $T$ cell subset counts in peripheral blood can be used as discriminatory biomarkers for diagnosis and severity prediction of COVID-19. J Infect Dis. 2020;222(2):198202.

46 Wan S, Yi Q, Fan S, Lv J, Zhang X, Guo L, et al. Relationships among lymphocyte subsets, cytokines, and the pulmonary inflammation index in coronavirus (COVID-19) infected patients. Br J Haematol. 2020 May; 189(3): 428-37.

47 Liu J, Li S, Liu J, Liang B, Wang X, Wang H, et al. Longitudinal characteristics of lymphocyte responses and cytokine profiles in the peripheral blood of SARS-CoV-2 infected patients. EBioMedicine. 2020 May;55:102763.

48 Wang F, Nie J, Wang H, Zhao Q, Xiong Y, Deng L, et al. Characteristics of peripheral lymphocyte subset alteration in COVID-19 pneumonia. J Infect Dis. 2020 May;221(11): $1762-9$.

49 Ling Y, Xu SB, Lin YX, Tian D, Zhu ZQ, Dai $\mathrm{FH}$, et al. Persistence and clearance of viral RNA in 2019 novel coronavirus disease rehabilitation patients. Chin Med J (Engl). 2020 May;133(9):1039-43.

50 Zheng M, Gao Y, Wang G, Song G, Liu S, Sun $D$, et al. Functional exhaustion of antiviral lymphocytes in COVID-19 patients. Cell Mol Immunol. 2020 May; 17(5):533-5.

51 Channappanavar R, Zhao J, Perlman S. T cellmediated immune response to respiratory coronaviruses. Immunol Res. 2014 Aug;59(13):118-28.

52 Cao X. COVID-19: immunopathology and its implications for therapy. Nat Rev Immunol. 2020 May;20(5):269-70.

53 Henry BM, de Oliveira MH, Benoit S, Plebani M, Lippi G. Hematologic, biochemical and immune biomarker abnormalities associated with severe illness and mortality in coronavirus disease 2019 (COVID-19): a meta-analysis. Clin Chem Lab Med. 2020 Jun;58(7): 1021-8.

54 Lippi G, Plebani M, Henry BM. Thrombocytopenia is associated with severe coronavirus disease 2019 (COVID-19) infections: a metaanalysis. Clin Chim Acta. 2020 Jul;506:145-8.
55 Metlay JP, Waterer GW, Long AC, Anzueto A, Brozek J, Crothers K, et al. Diagnosis and Treatment of Adults with Community-acquired Pneumonia. An Official Clinical Practice Guideline of the American Thoracic Society and Infectious Diseases Society of America. Am J Respir Crit Care Med. 2019 Oct; 200(7):e45-67.

56 Yang X, Yang Q, Wang Y, Wu Y, Xu J, Yu Y, et al. Thrombocytopenia and its association with mortality in patients with COVID-19. J Thromb Haemost. 2020 Jun;18(6):1469-72.

57 Li Q, Cao Y, Chen L, Wu D, Yu J, Wang H, et al. Hematological features of persons with COVID-19. Leukemia. 2020 Jun.

58 Liu Y, Sun W, Guo Y, Chen L, Zhang L, Zhao $S$, et al. Association between platelet parameters and mortality in coronavirus disease 2019: retrospective cohort study. Platelets. 2020 May;31(4):490-6.

59 Qu R, Ling Y, Zhang YH, Wei LY, Chen X, Li $\mathrm{XM}$, et al. Platelet-to-lymphocyte ratio is associated with prognosis in patients with coronavirus disease-19. J Med Virol. 2020 Mar;jmv.25767.

60 Yang AP, Liu JP, Tao WQ, Li HM. The diagnostic and predictive role of NLR, d-NLR and PLR in COVID-19 patients. Int Immunopharmacol. 2020 Jul;84:106504.

61 Yang M, Hon KL, Li K, Fok TF, Li CK. The effect of SARS coronavirus on blood system: its clinical findings and the pathophysiologic hypothesis. Zhongguo Shi Yan Xue Ye Xue Za Zhi. 2003 Jun;11(3):217-21.

62 Yang M, Ng MH, Li CK. Thrombocytopenia in patients with severe acute respiratory syndrome (review). Hematology. 2005 Apr; 10(2):101-5.

63 Chen RF, Chang JC, Yeh WT, Lee CH, Liu JW, Eng HL, et al. Role of vascular cell adhesion molecules and leukocyte apoptosis in the lymphopenia and thrombocytopenia of patients with severe acute respiratory syndrome (SARS). Microbes Infect. 2006 Jan;8(1):1227.

64 Xu P, Zhou Q, Xu J. Mechanism of thrombocytopenia in COVID-19 patients. Ann Hematol. 2020 Jun;99(6):1205-8.

65 Mehta P, McAuley DF, Brown M, Sanchez E, Tattersall RS, Manson JJ; HLH Across Speciality Collaboration, UK. COVID-19: consider cytokine storm syndromes and immunosuppression. Lancet. 2020 Mar;395(10229): 1033-4.

66 Wada H, Thachil J, Di Nisio M, Mathew P, Kurosawa S, Gando S, et al.; The Scientific Standardization Committee on DIC of the International Society on Thrombosis Haemostasis. Guidance for diagnosis and treatment of DIC from harmonization of the recommendations from three guidelines. J Thromb Haemost. 2013 Feb. https://doi.org/10.1111/ jth.12155. 
67 Fan BE, Ong KH, Chan SS, Young BE, Chong VC, Chen SP, et al. Blood and blood product use during COVID-19 infection. Am J Hematol. 2020 Jul;95(7):E158-60.

68 Lazarian G, Quinquenel A, Bellal M, Siavellis J, Jacquy C, Re D, et al. Autoimmune haemolytic anaemia associated with COVID-19 infection. Br J Haematol. 2020 Jul;190(1):29-31.

69 Xiao F, Tang M, Zheng X, Liu Y, Li X, Shan H. Evidence for Gastrointestinal Infection of SARS-CoV-2. Gastroenterology. 2020;158(6): 1831-3.e3.

70 Lin L, Jiang X, Zhang Z, Huang S, Zhang Z, Fang Z, et al. Gastrointestinal symptoms of 95 cases with SARS-CoV-2 infection. Gut. 2020 Jun;69(6):997-1001.

71 Khalili JS, Zhu H, Mak NS, Yan Y, Zhu Y. Novel coronavirus treatment with ribavirin: groundwork for an evaluation concerning COVID-19. J Med Virol. 2020 Jul;92(7):740-

72 Lu CC, Chen MY, Lee WS, Chang YL. Potential therapeutic agents against COVID-19: what we know so far. J Chin Med Assoc. 2020 Jun;83(6):534-6.

73 Wong RS, Wu A, To KF, Lee N, Lam CW, Wong CK, et al. Haematological manifestations in patients with severe acute respiratory syndrome: retrospective analysis. BMJ. 2003 Jun;326(7403):1358-62.

74 Zeng YM, Xu XL, He XQ, Tang SQ, Li Y, Huang YQ, et al. Comparative effectiveness and safety of ribavirin plus interferon-alpha, lopinavir/ritonavir plus interferon-alpha, and ribavirin plus lopinavir/ritonavir plus interferon-alpha in patients with mild to moderate novel coronavirus disease 2019: study protocol. Chin Med J (Engl). 2020 May; 133(9): $1132-4$.

75 Myles N, von Wielligh J, Kyriacou M, Ventrice T, To LB. A cohort study assessing the impact of small volume blood tubes on diagnostic test quality and iatrogenic blood loss in a cohort of adult haematology patients. Intern Med J. 2018 Jul;48(7):817-21.

76 Litton E, Latham P, Inman J, Luo J, Allan P. Safety and efficacy of erythropoiesis-stimulating agents in critically ill patients admitted to the intensive care unit: a systematic review and meta-analysis. Intensive Care Med. 2019 Sep;45(9):1190-9.

77 Baron DM, Franchini M, Goobie SM, Javidroozi M, Klein AA, Lasocki S, et al. Patient blood management during the COVID-19 pandemic: a narrative review. Anaesthesia. 2020 Aug;75(8):1105-13.

78 Han H, Yang L, Liu R, Liu F, Wu KL, Li J, et al. Prominent changes in blood coagulation of patients with SARS-CoV-2 infection. Clin Chem Lab Med. 2020 Jun;58(7):1116-20.

79 Tang N, Li D, Wang X, Sun Z. Abnormal coagulation parameters are associated with poor prognosis in patients with novel coronavirus pneumonia. J Thromb Haemost. 2020 Apr; 18(4):844-7.
80 Voves C, Wuillemin WA, Zeerleder S. International Society on Thrombosis and Haemostasis score for overt disseminated intravascular coagulation predicts organ dysfunction and fatality in sepsis patients. Blood Coagul Fibrinolysis. 2006 Sep;17(6):445-51.

81 Zhang L, Yan X, Fan Q, Liu H, Liu X, Liu Z, et al. D-dimer levels on admission to predict in-hospital mortality in patients with Covid-19. J Thromb Haemost. 2020 Jun;18(6): 1324-9.

82 Xiong M, Liang X, Wei YD. Changes in blood coagulation in patients with severe coronavirus disease 2019 (COVID-19): a meta-analysis. Br J Haematol. 2020 Jun;189(6):1050-2.

83 Spiezia L, Boscolo A, Poletto F, Cerruti L, Tiberio I, Campello E, et al. COVID-19-Related Severe Hypercoagulability in Patients Admitted to Intensive Care Unit for Acute Respiratory Failure. Thromb Haemost. 2020 Jun; 120(6):998-1000.

84 Giannis D, Ziogas IA, Gianni P. Coagulation disorders in coronavirus infected patients: COVID-19, SARS-CoV-1, MERS-CoV and lessons from the past. J Clin Virol. 2020 Jun; 127:104362.

85 Violi F, Pastori D, Cangemi R, Pignatelli P, Loffredo L. Hypercoagulation and Antithrombotic Treatment in Coronavirus 2019: A New Challenge. Thromb Haemost. 2020 Jun;120(6):949-56.

86 Tang N, Bai H, Chen X, Gong J, Li D, Sun Z. Anticoagulant treatment is associated with decreased mortality in severe coronavirus disease 2019 patients with coagulopathy. J Thromb Haemost. 2020 May;18(5):1094-9.

87 Iba T, Levy JH, Warkentin TE, Thachil J, van der Poll T, Levi M; Scientific and Standardization Committee on DIC, and the Scientific and Standardization Committee on Perioperative and Critical Care of the International Society on Thrombosis and Haemostasis. Diagnosis and management of sepsis-induced coagulopathy and disseminated intravascular coagulation. J Thromb Haemost. 2019 Nov; 17(11):1989-94.

88 Yin S, Huang M, Li D, Tang N. Difference of coagulation features between severe pneumonia induced by SARS-CoV2 and non-SARSCoV2. J Thromb Thrombolysis. 2020 Apr. https://doi.org/10.1007/s11239-020-02105-8.

89 Cui S, Chen S, Li X, Liu S, Wang F. Prevalence of venous thromboembolism in patients with severe novel coronavirus pneumonia. J Thromb Haemost. 2020 Jun;18(6):1421-4.

90 Klok FA, Kruip M, van der Meer NJ, Arbous MS, Gommers D, Kant KM, et al. Incidence of thrombotic complications in critically ill ICU patients with COVID-19. Thromb Res. 2020; 191:145-7.
91 Helms J, Tacquard C, Severac F, LeonardLorant I, Ohana M, Delabranche X, et al.; CRICS TRIGGERSEP Group (Clinical Research in Intensive Care and Sepsis Trial Group for Global Evaluation and Research in Sepsis). High risk of thrombosis in patients with severe SARS-CoV-2 infection: a multicenter prospective cohort study. Intensive Care Med. 2020 Jun;46(6):1089-98.

92 Llitjos JF, Leclerc M, Chochois C, Monsallier JM, Ramakers M, Auvray M, et al. High incidence of venous thromboembolic events in anticoagulated severe COVID-19 patients. J Thromb Haemost. 2020 Jul;18(7):1743-6.

93 Wichmann D, Sperhake JP, Lütgehetmann M, Steurer S, Edler C, Heinemann A, et al. Autopsy Findings and Venous Thromboembolism in Patients with COVID-19. Ann Intern Med. 2020 May;M20-2003.

94 Ackermann M, Verleden SE, Kuehnel M, Haverich A, Welte T, Laenger F, et al. Pulmonary Vascular Endothelialitis, Thrombosis, and Angiogenesis in Covid-19. N Engl J Med. 2020 Jul;383(2):120-8.

95 Siddamreddy S, Thotakura R, Dandu V, Kanuru S, Meegada S. Corona Virus Disease 2019 (COVID-19) Presenting as Acute ST Elevation Myocardial Infarction. Cureus. 2020 Apr;12(4):e7782.

96 Oxley TJ, Mocco J, Majidi S, Kellner CP, Shoirah H, Singh IP, et al. Large-Vessel Stroke as a Presenting Feature of Covid-19 in the Young. N Engl J Med. 2020 May; 382(20):e60.

97 Mao L, Jin H, Wang M, Hu Y, Chen S, He Q, et al. Neurologic Manifestations of Hospitalized Patients with Coronavirus Disease 2019 in Wuhan, China. JAMA Neurol. 2020 Apr 10;77(6):1-9.

98 Panigada M, Bottino N, Tagliabue P, Grasselli G, Novembrino C, Chantarangkul V, et al. Hypercoagulability of COVID-19 patients in intensive care unit: a report of thromboelastography findings and other parameters of hemostasis. J Thromb Haemost. 2020 Jul;18(7):1738-42.

99 Middeldorp S, Coppens M, van Haaps TF, Foppen M, Vlaar AP, Müller MC, et al. Incidence of venous thromboembolism in hospitalized patients with COVID-19. J Thromb Haemost. 2020 May;jth.14888.

100 Lodigiani C, Iapichino G, Carenzo L, Cecconi M, Ferrazzi P, Sebastian T, et al.; Humanitas COVID-19 Task Force. Venous and arterial thromboembolic complications in COVID-19 patients admitted to an academic hospital in Milan, Italy. Thromb Res. 2020 Jul;191:9-14.

101 Fogarty H, Townsend L, Ni Cheallaigh C, Bergin C, Martin-Loeches I, Browne P, et al. More on COVID-19 coagulopathy in Caucasian patients. Br J Haematol. 2020 Jun; 189(6):1060-1.

102 Thachil J, Tang N, Gando S, Falanga A, Cattaneo $\mathrm{M}$, Levi $\mathrm{M}$, et al. ISTH interim guidance on recognition and management of coagulopathy in COVID-19. J Thromb Haemost. 2020 May;18(5):1023-6. 
103 Testa S, Paoletti O, Giorgi-Pierfranceschi M, Pan A. Switch from oral anticoagulants to parenteral heparin in SARS-CoV-2 hospitalized patients. Intern Emerg Med. 2020 Apr. https://doi.org/10.1007/s11739-020-023311.

104 American Society of Hematology (ASH) recommendations on Coronavirus disease and COVID-19. Available from: https:// www.hematology.org/covid-19. Accessed on 8 May 2020.

105 Akima S, McLintock C, Hunt BJ. RE: ISTH interim guidance to recognition and management of coagulopathy in COVID-19. J Thromb Haemost. 2020 Apr;jth.14853.

106 Barrett CD, Moore HB, Yaffe MB, Moore EE. ISTH interim guidance on recognition and management of coagulopathy in COVID-19: a comment. J Thromb Haemost. 2020 Apr;jth.14860.

107 Zhai Z, Li C, Chen Y, Gerotziafas G, Zhang Z, Wan J, et al.; Prevention Treatment of VTE Associated with COVID-19 Infection Consensus Statement Group. Prevention and Treatment of Venous Thromboembolism Associated with Coronavirus Disease 2019 Infection: A Consensus Statement before Guidelines. Thromb Haemost. 2020 Jun;120(6):937-48.

108 Pagano MB, Hess JR, Tsang HC, Staley E, Gernsheimer T, Sen N, et al. Prepare to adapt: blood supply and transfusion support during the first 2 weeks of the 2019 novel coronavirus (COVID-19) pandemic affecting Washington State. Transfusion. 2020 May;60(5):908-11.

109 Mohammadi S, Tabatabaei Yazdi SM, Eshghi $\mathrm{P}$, Norooznezhad AH. Coronavirus disease 2019 (COVID-19) and decrease in blood donation: experience of Iranian Blood Transfusion Organization (IBTO). Vox Sang. 2020 Apr;vox.12930.

110 Chang L, Yan Y, Wang L. Coronavirus Disease 2019: Coronaviruses and Blood Safety. Transfus Med Rev. 2020 Apr;34(2):75-80.
111 American Association of Blood Bank (AABB)'s Coronavirus Resources. Available from: http://www.aabb.org/advocacy/regulatorygovernment/Pages/AABB-Coronavirus-Resources.aspx. Accessed on 8 May 2020.

112 Keil SD, Ragan I, Yonemura S, Hartson L, Dart NK, Bowen R. Inactivation of severe acute respiratory syndrome coronavirus 2 in plasma and platelet products using a riboflavin and ultraviolet light-based photochemicaltreatment. VoxSang.2020 Apr;vox.12937.

113 He W, Chen L, Chen L, Yuan G, Fang Y, Chen W, et al. COVID-19 in persons with haematological cancers. Leukemia. 2020 Jun;34(6):1637-45.

114 Gale RP. Perspective: SARS-CoV-2, COVID-19 and Haematologists. Acta Haematol. 2020 May 6;1-4.

115 Li W, Wang D, Guo J, Yuan G, Yang Z, Gale RP, et al.; Hubei Anti-Cancer Association. COVID-19 in persons with chronic myeloid leukaemia. Leukemia. 2020 Jul;34(7):1799804.

116 Stukel TA, Schull MJ, Guttmann A, Alter DA, Li P, Vermeulen MJ, et al. Health impact of hospital restrictions on seriously ill hospitalized patients: lessons from the Toronto SARS outbreak. Med Care. 2008 Sep; 46(9):991-7.

117 Hanna TP, Evans GA, Booth CM. Cancer, COVID-19 and the precautionary principle: prioritizing treatment during a global pandemic. Nat Rev Clin Oncol. 2020 May;17(5): 268-70.

118 Terpos E, Engelhardt M, Cook G, Gay F, Mateos MV, Ntanasis-Stathopoulos I, et al. Management of patients with multiple myeloma in the era of COVID-19 pandemic: a consensus paper from the European Myeloma Network (EMN). Leukemia. 2020 May. https://doi.org/10.1038/s41375-020-0876-Z.

119 International Myeloma Society Recommendations for the Management of Myeloma Patients during the COVID-19 Pandemic. 2020. Available from: https://cms.cws.net/ content/beta.myelomasociety.org/files/ IMS\%20recommendations\%20for\%20Physicians\%20Final.pdf. Accessed on 8 May 2020.
120 European Hematology Association (EHA) COVID-19 Hematology Hub. Available from: https://ehaweb.org/. Accessed on 6 June 2020.

121 Dombret H. Granulocyte colony-stimulating factor in combination with intensive chemotherapy in the treatment of acute myeloid leukemia. Leuk Res. 1998 Dec;22(12): 1137-42.

122 Wang L, Baser O, Kutikova L, Page JH, Barron R. The impact of primary prophylaxis with granulocyte colony-stimulating factors on febrile neutropenia during chemotherapy: a systematic review and meta-analysis of randomized controlled trials. Support Care Cancer. 2015 Nov;23(11):3131-40.

123 Jazieh AR, Al Hadab A, Al Olayan A, AlHejazi A, Al Safi F, Al Qarni A, et al. Managing Oncology Services during a Major Coronavirus Outbreak: Lessons from the Saudi Arabia Experience. JCO Glob Oncol. 2020 Mar; 6(6):518-24.

124 Medd P, Nagra S, Hollyman D, Craddock C, Malladi R. Cryopreservation of allogeneic PBSC from related and unrelated donors is associated with delayed platelet engraftment but has no impact on survival. Bone Marrow Transplant. 2013 Feb;48(2):243-8.

125 Stockschläder M, Hassan HT, Krog C, Krüger W, Löliger C, Horstman M, et al. Long-term follow-up of leukaemia patients after related cryopreserved allogeneic bone marrow transplantation. Br J Haematol. 1997 Feb;96(2):382-6.

126 Koh M, Aljurf M, Greinix H, Weisdord D. Coronavirus and Haematopoietic Stem Cell Transplantation. Worldwide Network for Blood \& Marrow Transplantation. WBMT; 2020.

127 Coronavirus disease COVID-19: European Society for Blood and Marrow Transplantation (EBMT) Recommendations Update May 18, 2020. Available from: https://www. ebmt.org/sites/default/files/2020-05/ EBMT\%20COVID-19\%20guidelines\%20 v.8.1.2\%20\%282020-05-17\%29.pdf. Accessed on 6 June 2020. 